\title{
The Reliability and Validity of the Australian Moral Disengagement Scale
}

\author{
Nicola C. Newton,' Lexine A. Stapinski, Katrina E. Champion,' \\ Maree Teesson' and Kay Bussey ${ }^{2}$ \\ ${ }^{\prime}$ NHMRC Centre of Research Excellence in Mental Health and Substance Use, National Drug and \\ Alcohol Research Centre, UNSW Australia, Sydney, New South Wales, Australia \\ 2 Macquarie University, Sydney, New South Wales, Australia
}

\begin{abstract}
Background: The present study explored the reliability, validity, and factor structure of a modified version of the Moral Disengagement Scale (MDS), which comprehensively assesses proneness to disengage from different forms of conduct specific to Australian adolescents. Methods: A sample of 452 students $\left(\mathrm{M}_{\mathrm{age}}=12.79 ; \mathrm{SD}=\right.$ 1.93) completed the modified MDS and the Australian Self-Report Delinquency Scale. A multistep approach was used to evaluate the factor structure of the MDS. The sample was divided into exploratory $(n=221)$ and cross-validation samples $(n=231)$. Principal component analysis was conducted with the exploratory sample and multiple factor solutions compared to determine the optimal factor structure of the modified MDS. The final factor solution was confirmed in the cross-validation sample using confirmatory factor analysis. Internal consistency of the final scale and convergent validity with the delinquency questionnaire was also assessed. Results: Analyses resulted in a 22-item MDS for use in Australia, with four factors mapping onto the four conceptual categories of moral disengagement. The individual subscales demonstrated adequate to good internal consistency, and the total scale also demonstrated high internal consistency $(\alpha=0.87)$. Convergent validity of the scale was established. Conclusions: The 22-item Australian MDS is a reliable and valid instrument for use within an Australian population.
\end{abstract}

Keywords: moral disengagement, delinquency, factor analysis, psychometrics, adolescence

Improving our understanding of why some adolescents engage in deviant behaviours, such as delinquency, aggression and substance use, while others do not, is crucial for the development of successful prevention and intervention programs. Several factors have been associated with the development of deviant adolescent behaviour, including genetic risk factors, individual factors, and environmental or contextual factors (Arthur, Hawkins, Pollard, Catalano, \& Baglioni, 2002; Herrenkohl et al., 2000; Jessor, 1992). In recent years, moral disengagement (MD) has received considerable interest due to its ability to predict delinquent behaviour and substance use (Bandura, Barbaranelli, Caprara, \& Pastorelli, 1996a; Newton, Barrett, Swaffield, \& Teesson, 2014; Newton \& Bussey, 2006; Newton, Havard, \& Teesson, 2012; Pelton, Gound, Forehand, \& Brody, 2004).

Moral disengagement is defined as the tendency to disengage from moral selfcontrol and responsibility that ordinarily regulate behaviour (Bandura, Barbaranelli,

Address for correspondence: Nicola C. Newton: NHMRC Centre of Research Excellence in Mental Health and Substance Use, National Drug and Alcohol Research Centre, UNSW, 22-32 King Street, Randwick NSW 2031, Australia.Email: n.newton@unsw.edu.au

Behaviour Change I Volume 33 | Number 3 | 2016 | pp. 136-149 I (C) The Author(s) 2016 doi $10.1017 /$ bec.2016.9 
Caprara, \& Pastorelli, 2001; Pelton et al., 2004). During the process of socialisation, people adopt moral and social standards that serve as guides and deterrents for their actions (Bandura et al., 1996a). People apply these standards to everyday life, and it is through the anticipation of self-sanctions, such as guilt and blame, for not adhering to these standards that conduct is kept in line with their personal standards. However, there are many psychological processes that prevent these self-sanctions from being activated or operated (Bandura et al., 1996a). Social cognitive theory specifies eight mechanisms clustered into four major points in the self-regulatory control of moral behaviour through which MD can occur. Self-sanctions can be disengaged from immoral conduct by: (1) reconstructing the conduct, through moral justifications, euphemistic labelling or advantageous comparisons; (2) obscuring personal causal agency, through displacing or diffusing responsibility; (3) misrepresenting or disregarding the injurious consequences of one's actions, by disregarding or distorting responsibility; or (4) blaming and devaluating recipients of behaviour, by vilifying the recipients of maltreatment through dehumanising or attributing blame to them (Bandura et al., 1996a).

A growing body of evidence has demonstrated associations between MD and delinquency (Pelton et al., 2004; Shulman, Cauffman, Piquero, \& Fagan, 2011), aggression (Bandura et al., 1996a; Barchia \& Bussey, 2011; Gini, Pozzoli, \& Hymel, 2014; Obermann, 2011; Paciello, Fida, Tramontano, Lupinetti, \& Caprara, 2008; Pornari \& Wood, 2010), and alcohol and other drug use, including underage drinking among schoolchildren and adolescents (Barnes, Welte, Hoffman, \& Dintcheff, 1999; Newton et al., 2014; Newton et al., 2012; Passini, 2012). Bandura and colleagues (Bandura et al., 1996a) were the first to develop a self-report Moral Disengagement Scale (MDS) to evaluate the disinhibitory effects of the four components of MD in relation to transgressive behaviour (Pelton et al., 2004). The MDS has been adapted for use among schoolchildren and adolescents (Paciello et al., 2008), and variants have been used in many different contexts and with a range of behaviours, including sport (Lucidi et al., 2008) and underage drinking (Quinn \& Bussey, 2015). Studies that have examined the factor structure of measures of MD have identified a number of different structures (Boardley \& Kavussanu, 2007). Many studies in this area have proposed a unidimensional solution (Bandura et al., 1996a; Paciello et al., 2008); however, a fourfactor solution, which corresponds with the four sets of MD mechanisms identified in Bandura's conceptual model, has been proposed in other studies examining MD (McAlister, Bandura, \& Owen, 2006; Osofsky, Bandura, \& Zimbardo, 2005; Pozzoli, Gini, \& Vieno, 2012). In addition, an eight-dimension solution representing the eight mechanisms of MD proposed by Bandura (1991) could also logically be considered (Boardley \& Kavussanu, 2007).

The focus of the present study is on modified version of the MDS, which includes items specific to Australian children's antisocial and criminal conduct (NSW Attorney General's Department, 2003; Wagland \& Bussey, 2005; Wagland \& Bussey, 2015). These items relate to the most commonly publicised transgressions called before the New South Wales (NSW) Children's Courts, and represent aspects of common delinquent behaviour in Australia that are not currently assessed in Bandura's original MDS (Bandura et al., 1996a). Although this modified version of the MDS for Australia is a potentially useful tool, particularly among samples where delinquent behaviour is an issue of concern, it is important to examine the psychometric properties of the scale and validate the addition of the criminal and antisocial items against other measures of delinquency. Establishing the psychometric properties of a scale involves assessing its reliability and validity. Construct validity refers to the extent to which a measure is 
related to another variable with which it should theoretically be associated (Cronbach $\&$ Meehl, 1955). Previous research has shown that high scores on MD are significantly associated with increased delinquent behaviour (Pelton et al., 2004; Shulman et al., 2011). Given that the adapted MDS purports to measure delinquency, it is expected that the MDS would be positively correlated with other measures of delinquency (DeVellis, 2003). The present study sought to establish the construct validity of the adapted MDS using the Australian Self-Report Delinquency Scale (Mak, 1993), a culturally relevant measure of delinquent behaviour among Australian adolescents. The overall aim of the present study was to explore the factor structure, reliability (internal consistency), and validity of a version of the MDS adapted for the Australian context.

\section{Method}

\section{Participants}

A total of 452 participants were recruited from five Sydney independent (private) schools. Letters outlining the aims of study were sent to principals at a random selection of Sydney independent schools. Once principals approved the study, assessment times were arranged and information and consent forms were distributed to students' parents or guardians. Only those students who received parental consent were eligible to participate. All aspects of the study were approved by the administering research institution's Human Research Ethics Committee.

Thirty-nine cases were excluded from the confirmatory factor analysis procedures due to missing data on individual items.

\section{Assessment and Measures}

Participants completed the self-report survey using paper and pencil in a classroom setting supervised by a member of the research team.

Demographics. Participants' gender, age and country of birth were measured.

Moral disengagement (MD). Moral disengagement was measured using a 39-item scale that assessed proneness to disengage from different forms of detrimental conduct in diverse contexts and interpersonal relationships. Bandura's (1995) original MDS consisted of 32 items, 31 of which were used in the current study. One item was omitted due to ethical concerns related to 'getting high'. Consistent with previous research on MD in Australia, an additional eight items relating to the most commonly publicised transgressions called before the NSW Children's Courts in 2003, including arson, theft, property offence, and assault, were included (see Table 1; NSW Attorney General's Department, 2003; Wagland \& Bussey, 2005). Items in the revised scale covered the four major points in the self-regulatory system identified by Bandura and colleagues (1996) where internal moral control can be disengaged from detrimental conduct. These included: reconstructing the conduct, obscuring personal causal agency, misrepresenting or disregarding the injurious consequences of one's action, and vilifying the recipients of maltreatment by blaming and devaluating them. Participants rated each item on a 4-point Likert scale, indicating their degree of acceptance of moral exonerations for such conduct from 0 (strongly disagree) to 3 (strongly agree).

Australian Self-Reported Delinquency Scale (Mak, 1990) ${ }^{1}$. The Australian SelfReported Delinquency Scale contains 34 items designed to examine delinquent 


\section{TABLE 1}

Factor Structure of a Modified Version of the Moral Disengagement Scale

\begin{tabular}{|c|c|c|c|c|c|}
\hline & \multicolumn{4}{|c|}{ Component/Factor } & \multirow{2}{*}{$\begin{array}{l}\text { Factor in } \\
\text { final scale }\end{array}$} \\
\hline & 1 & 2 & 3 & 4 & \\
\hline $\begin{array}{l}\text { 1. It is all right to fight to protect your } \\
\text { friends. }\end{array}$ & -.022 & .052 & .672 & .059 & 3 \\
\hline $\begin{array}{l}\text { 2. Slapping and shoving someone is just a } \\
\text { way of joking. }\end{array}$ & .105 & .159 & .718 & .075 & 3 \\
\hline $\begin{array}{l}\text { 3. If someone has lots of money it doesn't } \\
\text { matter if you damage their things. }{ }^{\text {a }}\end{array}$ & .090 & .761 & .311 & .161 & 2 \\
\hline $\begin{array}{l}\text { 4. It's okay to damage people's property } \\
\text { because insurance companies pay to fix } \text { it. }^{\text {a }}\end{array}$ & .233 & .771 & .235 & .073 & 2 \\
\hline $\begin{array}{l}\text { 5. Damaging some property is no big deal } \\
\text { when you consider that others are } \\
\text { beating people up. }\end{array}$ & .251 & .736 & .275 & .148 & 2 \\
\hline $\begin{array}{l}\text { 6. It's okay to light fires because the fire } \\
\text { brigade will put them out. }^{\text {a }}\end{array}$ & .285 & .757 & .088 & -.023 & 2 \\
\hline $\begin{array}{l}\text { 7. One kid in a gang should not be blamed } \\
\text { for the trouble that the whole gang } \\
\text { causes. }\end{array}$ & -.050 & .128 & -.019 & .506 & 4 \\
\hline $\begin{array}{l}\text { 8. If kids are living under bad conditions } \\
\text { they cannot be blamed for behaving } \\
\text { aggressively. }\end{array}$ & -.128 & .214 & -.113 & .602 & 4 \\
\hline $\begin{array}{l}\text { 9. It is okay to tell small lies because they } \\
\text { don't really do any harm. }\end{array}$ & .174 & .273 & .401 & .374 & $\mathrm{~N} / \mathrm{A}$ \\
\hline $\begin{array}{l}\text { 10. Some people deserve to be treated like } \\
\text { animals. }\end{array}$ & .360 & .173 & .437 & .048 & $\mathrm{~N} / \mathrm{A}$ \\
\hline $\begin{array}{l}\text { 11. Rich people deserve to have their things } \\
\text { damaged. } \text {. }^{\text {a }}\end{array}$ & .226 & .591 & .328 & .189 & 2 \\
\hline $\begin{array}{l}\text { 12. If kids fight and misbehave in school it is } \\
\text { their teachers fault. }\end{array}$ & .440 & .194 & .389 & .307 & $\mathrm{~N} / \mathrm{A}$ \\
\hline $\begin{array}{l}\text { 13. It is all right to beat someone who bad } \\
\text { mouths your family. }\end{array}$ & .287 & .189 & .715 & .054 & 3 \\
\hline $\begin{array}{l}\text { 14. To hit an annoying classmate is just } \\
\text { teaching them 'a lesson'. }\end{array}$ & .280 & .315 & .705 & .028 & 3 \\
\hline $\begin{array}{l}\text { 15. Stealing a little bit of money is not too } \\
\text { serious compared to those who steal a } \\
\text { lot of money. }\end{array}$ & .374 & .454 & .093 & .293 & $\mathrm{~N} / \mathrm{A}$ \\
\hline $\begin{array}{l}\text { 16. A kid who only suggests breaking rules } \\
\text { should not be blamed if other kids go } \\
\text { ahead and do it. }\end{array}$ & .289 & -.012 & .007 & .496 & $\mathrm{~N} / \mathrm{A}$ \\
\hline $\begin{array}{l}\text { 17. If kids have not been taught how to } \\
\text { behave properly they should not be } \\
\text { blamed for misbehaving. }\end{array}$ & .182 & -.038 & .167 & .614 & 4 \\
\hline $\begin{array}{l}\text { 18. Setting fires in the bush is okay because } \\
\text { it's not as bad as burning someone's } \\
\text { house down. }{ }^{\text {a }}\end{array}$ & .482 & .533 & -.013 & -.049 & $\mathrm{~N} / \mathrm{A}$ \\
\hline
\end{tabular}




\section{TABLE 1}

Continued

\begin{tabular}{|c|c|c|c|c|c|}
\hline & \multicolumn{4}{|c|}{ Component/Factor } & \multirow{2}{*}{$\begin{array}{l}\text { Factor in } \\
\text { final scale }\end{array}$} \\
\hline & 1 & 2 & 3 & 4 & \\
\hline $\begin{array}{l}\text { 19. Children do not mind being teased } \\
\text { because it shows other kids are } \\
\text { interested in them. }\end{array}$ & .707 & .080 & .092 & .004 & 1 \\
\hline $\begin{array}{l}\text { 20. It is okay to treat somebody badly who } \\
\text { behaves like a pest. }\end{array}$ & .649 & .088 & .351 & .053 & 1 \\
\hline $\begin{array}{l}\text { 21. If people are careless where they leave } \\
\text { their things it is their own fault if they get } \\
\text { stolen. }\end{array}$ & .344 & .094 & .203 & .344 & $\mathrm{~N} / \mathrm{A}$ \\
\hline $\begin{array}{l}\text { 22. Damaging people's things is a good way } \\
\text { to impress your friends. }{ }^{\text {a }}\end{array}$ & .574 & .398 & .213 & .024 & $\mathrm{~N} / \mathrm{A}$ \\
\hline $\begin{array}{l}\text { 23. It is all right to fight when your group's } \\
\text { honour is threatened. }\end{array}$ & .401 & .228 & .586 & .095 & 3 \\
\hline $\begin{array}{l}\text { 24. Taking someone's bicycle without their } \\
\text { permission is just 'borrowing it'. }\end{array}$ & .563 & .318 & .179 & .144 & 1 \\
\hline $\begin{array}{l}\text { 25. It is okay to say bad things to a classmate } \\
\text { because hitting them is worse. }\end{array}$ & .453 & .284 & .392 & .235 & $\mathrm{~N} / \mathrm{A}$ \\
\hline $\begin{array}{l}\text { 26. If a group decides together to do } \\
\text { something really bad it is unfair to blame } \\
\text { a single kid in the group for it. }\end{array}$ & -.062 & -.068 & .076 & .723 & 4 \\
\hline $\begin{array}{l}\text { 27. Kids cannot be blamed for using bad } \\
\text { words when all their friends do it. }\end{array}$ & .340 & .015 & .185 & .593 & N/A \\
\hline $\begin{array}{l}\text { 28. Teasing someone does not really hurt } \\
\text { them. }\end{array}$ & .637 & .229 & .186 & .099 & 1 \\
\hline $\begin{array}{l}\text { 29. Lighting fires isn't really that bad } \\
\text { because no one really gets hurt. }^{\text {a }}\end{array}$ & .628 & .360 & -.028 & .013 & N/A \\
\hline $\begin{array}{l}\text { 30. Someone who is mean and rude does not } \\
\text { deserve to be treated like a human being. }\end{array}$ & .494 & .102 & .385 & .133 & $N / A$ \\
\hline $\begin{array}{l}\text { 31. Kids who are treated badly usually do } \\
\text { things to deserve it. }\end{array}$ & .624 & .091 & .279 & .216 & 1 \\
\hline $\begin{array}{l}\text { 32. It is all right to lie to keep your friends out } \\
\text { of trouble. }\end{array}$ & .296 & .075 & .487 & .369 & N/A \\
\hline $\begin{array}{l}\text { 33. Compared to the very bad things some } \\
\text { people do, taking some things from a } \\
\text { shop without paying is not very serious. }\end{array}$ & .503 & .342 & .069 & .233 & $\mathrm{~N} / \mathrm{A}$ \\
\hline $\begin{array}{l}\text { 34. It is unfair to blame a child who had only } \\
\text { a small part in the harm caused by a } \\
\text { group. }\end{array}$ & -.023 & .112 & .132 & .671 & 4 \\
\hline $\begin{array}{l}\text { 35. Kids cannot be blamed for misbehaving } \\
\text { if their friends pressured them to do it. }\end{array}$ & .276 & .097 & .066 & .557 & N/A \\
\hline $\begin{array}{l}\text { 36. It's okay to light fires because if 'your' fire } \\
\text { makes the news then that means your } \\
\text { friends will be really impressed. }\end{array}$ & .508 & .342 & .113 & .038 & $\mathrm{~N} / \mathrm{A}$ \\
\hline
\end{tabular}


TABLE 1

Continued

\begin{tabular}{lcccccc}
\hline & \multicolumn{5}{c}{ Component/Factor } & \\
\cline { 2 - 5 } & 1 & 2 & 3 & 4 & $\begin{array}{l}\text { Factor in } \\
\text { final scale }\end{array}$ \\
\hline $\begin{array}{l}\text { 37. Saying bad things about other kids } \\
\text { doesn't hurt anyone. }\end{array}$ & .565 & .370 & .270 & .119 & 1 \\
$\begin{array}{l}\text { 38. Some people have to be treated roughly } \\
\text { because they lack feelings that can be } \\
\text { hurt. }\end{array}$ & .728 & .119 & .188 & .175 & 1 \\
$\begin{array}{l}\text { 39. Children are not at fault for misbehaving } \\
\text { if their parents are too strict with them. }\end{array}$ & .372 & .065 & .234 & .463 & $\mathrm{~N} / \mathrm{A}$ \\
\hline
\end{tabular}

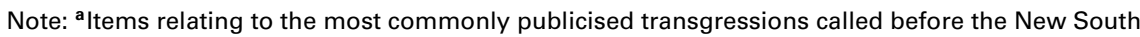
Wales (NSW) Children's Courts.

behaviour ranging from minor status offences to more serious crimes. It includes nine subscales: cheating, status offences, fighting, stealing of vehicles and parts, drug use, theft, harming others, driving offences, and acts of vandalism and disturbance (Mak, 1993). Participants were required to indicate whether they had been involved in each delinquent activity during the past 12 months (Yes/No). For ethical reasons, four items were omitted from the scale. The elimination of two of these items, which related to the use of 'barbiturates' and 'LSD', is consistent with previous research that found these items to have minimal effect on the overall delinquency score (Carroll, Durkin, Houghton, \& Hattie, 1996). The other two items related to forcing sexual acts on another person and driving a car when drunk. Four 'lie' items were interspersed among the delinquency items to detect unusually high levels of social desirability. Previous research has found the scale to have high construct validity and a clear ninefactor structure relating to the nine subscales, with all items loading between 31 to .75 (Mak, 1993). In the present study, this scale demonstrated high internal reliability $(\alpha=0.88)$.

\section{Statistical Analysis}

Descriptive analyses and investigations of skewness and kurtosis were performed using SPSS v22. A multistep approach was used to evaluate the factor structure of the adapted Australian version of the MDS. Using the random selection function in SPSS, the sample was divided into an exploratory sample and a cross-validation sample ( $n$ $=221$ and $n=231$ respectively). Independent samples $t$ tests and chi-squared tests were used to compare the split samples (exploratory and cross-validation samples) on all variables. First, principal component analysis (PCA) with varimax rotation was conducted using SPSS with the exploratory sample to determine the factor structure of the adapted MDS. Number of components retained was determined with reference to the resulting eigenvalues, Cattell's (1966) scree plot, and component interpretability. Due to high skewness for some items, the factor solution was verified using the FACTOR package, which allows the application of PCA based on polychoric correlations (as recommended by Baglin, 2014). To determine the optimal factor solution, model fit for multiple factor solutions were compared within a confirmatory factor analysis framework using AMOS. A root mean square error of approximation 
(RMSEA) value less than .08 , chi-square to degrees of freedom ratio $\left(\chi^{2} / d f\right)$ below 2 , parsimony-adjusted comparative fit index (PCFI) greater than 0.5 , and comparative fit index (CFI) values greater than .90 are considered indices of an acceptable model fit (Byrne, 2010). The expected cross-validation index was also used to compare models (lower values indicate lower expected discrepancy between analysed sample and another from the same population). Scale refinement was informed by modification indices and individual item loadings. Items that loaded more than 0.5 were retained in the factor on which they had the highest loading. Although item loadings of 0.3 to 0.4 are generally considered acceptable (Bryant \& Yarnold, 2004); the more conservative item loading of 0.5 used in this study is consistent with research that has found the size of item loadings (component saturation) to be the most important influence on pattern stability under a broad range of manipulations (Fava \& Velicer, 1992a, 1992b; Guagdagnoli \& Velicer, 1988; Velicer \& Fava, 1987). Items with high modification indices $(>10)$ were also reviewed.

The final factor solution was then confirmed in the cross-validation sample using AMOS confirmatory factor analysis and with reference to model fit indices as described above. The internal reliability of the MDS revised subscales were assessed using Cronbach's alpha, and construct validity of the scale was examined by calculating Pearson correlations between MDS scores and an existing validated measure of delinquency, the Australian Self-Report Delinquency Scale.

\section{Results}

\section{Descriptive Characteristics}

Participants ranged in age from 10 to 15 years (mean age of 12.79 years; SD $=1.93$ ) and $50 \%$ were female. A total of 179 students were from Year 5 classes in primary schools (mean age $=10.49, S D=.54$ ), and the remaining 273 participants were from Year 9 classes in secondary schools (mean age of $14.29, \mathrm{SD}=.47$ ). The majority of participants were of Australian descent $(61.2 \%)$, with the high minority groups being of British (14.6\%) and Chinese $(8.5 \%)$ descent. Independent samples $t$ tests and chi-squared tests indicated no significant differences between the exploratory and confirmatory sample on any demographic or variables of interest, supporting the similarity of the subsamples (all $p$ values $<.05$ ).

\section{Factor Structure of the Adapted MDS}

Exploratory factor analyses conducted in the exploratory sample determined the structure of the adapted MDS. The Barlett's test of sphericity and the Kaiser-Meyer-Olkin (KMO) measure of sampling adequacy indicated the scale was suitable for factor analysis procedures, $\mathrm{KMO}=.90$, Barlett's $\chi^{2}(741, N=221)=4061, p<.001$. Principal component analysis (PCA) with varimax rotation revealed eight factors with eigenvalues greater than $1(12.7,3.0,1.9,1.8,1.5,1.2,1.1,1.1)$; however, visual inspection of the scree plot suggested a one- or four-factor solution. A Horn's parallel analysis (Watkins, 2000) compared the factor eigenvalues to the average eigenvalues produced from 100 random data sets. The parallel analysis further supported the four-factor solution, as only these eigenvalues were higher than the corresponding values generated in the parallel analysis. The four factors accounted for $32.5 \%, 7.7 \%$, $5.0 \%$ and $4.8 \%$ of the variance, respectively; factor loadings are presented in Table 1. Significant skewness was observed for 11 of the items, and thus the factor solution 
was verified using PCA based on polychoric correlations (Baglin, 2014), which also supported a four-factor solution.

To confirm the optimal structure, multiple-factor solutions were compared within a confirmatory factor analysis framework. One- and four-factor solutions were compared in view of PCA results and factor structure of the MDS that has been identified previously (Bandura, 1990; Osofsky et al., 2005; Paciello et al., 2008; Pozzoli et al., 2012). Comparison of model fit indices for the one-factor and four-factor solution reflected a superior fit to the data on all indices for the four-factor solution (see Table 2). The four-factor solution distinguished items according to the four dimensions proposed by Bandura et al. (1996a). The scale was further refined with reference to the psychometric properties of each item. Eleven items were dropped from the scale as they did not load over 0.5 on any factor; two items were deleted due to extreme skewness; and an additional four items were deleted due to high modification indices $(>10)$, suggesting cross-loading onto another factor. Model fit indices for the revised scale are reported in Table 2 and indicated the refinements improved fit to the data, with the final scale demonstrating adequate-to-good model fit.

The final scale is a 22-item MDS for use in Australia (the Australian MDS) with four subscales mapping onto the proposed dimensions: (1) reconstructing the conduct (factor 2, five items); (2) obscuring personal causal agency (factor 4, five items); (3) misrepresenting or disregarding the injurious consequences of one's actions (factor 3 , five items); and (4) blaming and devaluating recipients of behaviour (factor 1, seven items). The Australian MDS is reported in Table 1.

\section{Confirmatory Factor Analysis}

The stability of the four-factor solution was confirmed in the cross-validation sample. All 22 items loaded significantly on the factor to which they had been assigned. Goodness-of-fit indices for the four-factor model and comparison one-factor model are reported in Table 2 . The four-factor model demonstrated adequate-to-good fit to the data, and all fit indices indicated superior model fit for the four-factor compared to the one-factor solution.

\section{Factor Correlations and Internal Consistency}

The mean factor scores on the Australian MDS were $11.87(S D=4.23$, range 7-35) for factor 1 (blaming and devaluating), $6.96(\mathrm{SD}=2.73$, range 5-21) for factor 2 (reconstructing the conduct), 12.62 (SD $=4.22$, range 5-25) for factor 3 (misrepresenting or disregarding), and 14.91 ( $S D=4.08$, range 5-24) for factor 4 (obscuring personal agency). Table 3 reports correlations between the four factors of the scale; the factors were all significantly intercorrelated, with correlations ranging from .16 to .61 .

The internal consistency of the Australian MDS was measured using Cronbach's alpha. The alpha coefficients for factors $1-4$ were $0.83,0.85,0.82$ and 0.67 respectively, indicating good internal reliability for factors 1-3 and adequate reliability for the fourth factor. The total scale score also demonstrated high internal consistency $(\alpha=0.87)$ and was comparable to the internal consistency of the 39-item MDS $(\alpha=0.93)$, supporting the utility of the 22 -item short version of the scale. 


\section{TABLE 2}

Model Fit Statistics for Determining Optimal Factor Solution

\begin{tabular}{lrllllll}
\hline Sample and factor structure & \multicolumn{1}{c}{$\chi^{2}$} & $d f$ & $\chi^{2} / d f$ & CFI & PCFI & RMSEA [95\% Cl] & ECVI [95\% CI] \\
\hline Exploratory sample & & & & & & & \\
$\quad$ One-factor (39 items) & $1,948.93$ & 702 & 2.78 & 0.66 & 0.62 & $0.094[0.089,0.099]$ & $10.92[10.28,11.59]$ \\
$\quad$ Four-factor (39 items) & $1,433.67$ & 696 & 2.06 & 0.80 & 0.75 & $0.073[0.067,0.078]$ & $8.40[7.99,8.96]$ \\
$\quad$ Four-factor (revised, 22 items) & 393.53 & 203 & 1.94 & 0.90 & 0.79 & $0.069[0.058,0.079]$ & $2.69[2.43,2.99]$ \\
$\quad$ Cross-validation sample & & & & & & & \\
$\quad$ One-factor (revised, 22 items) & 696.11 & 230 & 3.03 & 0.74 & 0.67 & $0.098[0.090,0.106]$ & $3.95[3.60,4.35]$ \\
$\quad$ Four-factor (revised, 22 items) & 400.25 & 203 & 1.97 & 0.88 & 0.78 & $0.068[0.058,0.078]$ & $2.58[2.33,2.87]$ \\
\hline
\end{tabular}


TABLE 3

Correlations Between the MDS Subscales and Delinquency Scale

\begin{tabular}{|c|c|c|c|c|}
\hline & \multicolumn{4}{|c|}{ Moral Disengagement Scale } \\
\hline & $\begin{array}{l}\text { Blaming/ } \\
\text { devaluating }\end{array}$ & Reconstructing & $\begin{array}{l}\text { Misrepresenting/ } \\
\text { disregarding }\end{array}$ & $\begin{array}{l}\text { Obscuring } \\
\text { personal agency }\end{array}$ \\
\hline \multicolumn{5}{|l|}{ MDS } \\
\hline $\begin{array}{l}\text { Blaming/ } \\
\text { devaluating }\end{array}$ & - & & & \\
\hline Reconstructing & $.61^{* *}$ & - & & \\
\hline $\begin{array}{l}\text { Misrepresenting/ } \\
\text { disregarding }\end{array}$ & $.60^{* *}$ & $.56^{* *}$ & - & \\
\hline $\begin{array}{l}\text { Obscuring } \\
\text { personal agency }\end{array}$ & $.20^{* *}$ & $.16^{*}$ & $.20^{* *}$ & - \\
\hline $\begin{array}{l}\text { Australian } \\
\text { Delinquency } \\
\text { Scale }\end{array}$ & $.52^{* *}$ & $.48^{* *}$ & $.57^{* *}$ & $.15^{*}$ \\
\hline
\end{tabular}

Note: ${ }^{* *} p<.001,{ }^{*} p<.01$.

\section{Convergent Validity}

To assess convergent validity of the Australian MDS, correlations between each factor and Mak's (1990) Australian Self-Report Delinquency Scale are shown in Table 3. Significant correlations were observed between the delinquency questionnaire and all four factors of the Australian MDS. Correlations were strongest for factors 1-3 (blaming/devaluating, reconstructing, misrepresenting/disregarding), which demonstrated strong correlations with the delinquency questionnaire.

\section{Discussion}

This study explored the psychometric properties of a modified version of the MDS for use in Australia, particularly for use with delinquent samples or where antisocial behaviour is an issue of concern (Wagland \& Bussey, 2005; Wagland \& Bussey, 2015). This scale extends the Bandura's original MDS scale by including additional delinquency items mapped directly onto the offences most frequently reported by young people in an Australian context(Wagland \& Bussey, 2005). The results indicated that this scale could justifiably be reduced to 22 items with four factors each measuring a distinct aspect of MD (see Table 1). The first MD factor related to 'blaming and devaluating recipients of behaviour', the second factor related to 'reconstructing the conduct', the third factor related to MD through 'misrepresenting or disregarding the injurious consequences of one's actions', and the final factor related to 'obscuring personal causal agency'.

The present results indicated that the Australian MDS was best conceptualised as having four dimensions, replicating the four conceptual categories of moral disengagement suggested by Bandura and colleagues (1996a). These findings are also consistent with other research that have identified a four-factor solution (Paciello et al., 2008). The Australian MDS demonstrated excellent internal and good validity. When examined separately, each of the factors also displayed adequate to good 
internal reliability and they were correlated with one another, suggesting that together they measure an overall construct of MD. The construct validity of the Australian MDS was established by demonstrating convergent validity with a validated measure of delinquency. However, results from the reliability and validity analyses indicate that the fourth factor, 'obscuring personal causal agency', was less related to the other MDS factors and to the construct of delinquency. Although this finding was not evident in previous investigations of these four factors with an Italian sample (Pozzoli et al., 2012), and in prison (Osofsky et al., 2005) and military settings in the United States (McAlister et al., 2006), our data suggest that in the Australian context, the three factors representing blaming and devaluating recipients of behaviour, reconstructing the conduct, and misrepresenting or disregarding the injurious consequences of one's actions are the aspects of moral disengagement most strongly related to delinquent behaviour. Understanding the potential cross-cultural differences in the manifestation of MD and its association with delinquent behaviour is a promising direction for future research.

A common limitation of any instrument is the generalisability or representativeness of the sample in which the measure was developed or validated. The sample in this study was comprised only of students from independent Sydney schools. Although there is no standardised measure on which to compare Sydney schools on socio-economic status, students attending independent schools come predominately from high socio-economic backgrounds (Mukherjee, 1999). Despite this, evidence suggests that proneness to MD does not differ as a function of familial socioeconomic status (Bandura et al., 1996a). Future research that tests the factor structure of the Australian MDS among students from public schools (i.e., those governed by the NSW Department of Education and Communities) would help to determine the generalisability of the present results. Further, longitudinal data were unable to be obtained from the current study, precluding an examination of test-retest reliability. Longitudinal research could examine this issue in the future. Finally, the study research relied on self-report data and employed only one type of informant, which may have resulted in shared variance. Nevertheless, self-reports of transgressive conduct have been shown to correlate with alternative assessment methods such as behavioural observations by peers, teachers, and parents, lending support to the reliability of our measures of MDS and delinquency in this study (Bandura, Barbaranelli, Caprara, \& Pastorelli, 1996b).

\section{Conclusion}

The results of the present study support the use of the 22-item Australian MDS as a reliable and valid research instrument with an Australian population. Understanding the factors that contribute to delinquent behaviour in adolescents is crucial for developing successful prevention and early intervention programs to target these behaviours. Given the growing interest in the construct of MD in adolescent research,

146 the Australian MDS provides a useful, reliable and valid measure of MD for future research among Australian adolescents.

\section{Acknowledgments}

The authors would like to acknowledge the schools and students involved in the study and would also like to thank Greg Martin and Peter Gates for their assistance. N.N 
and L.S are supported by a Society for Mental Health 2015 Early Career Research Award.

\section{Conflicts of Interest}

None.

\section{Endnote}

1 Since the present study, the Australian Self-Reported Delinquency Scale has been revised, resulting in a 30-item scale with eight subscales (Curcio, Mak, \& Knott, 2015).

\section{References}

Arthur, M.W., Hawkins, J.D., Pollard, J.A., Catalano, R.F., \& Baglioni, A.J. (2002). Measuring risk and protective factors for use, delinquency, and other adolescent problem behaviors: The Communities That Care Youth Survey. Evaluation Review, 26, 575-601.

Baglin, J. (2014). Improving your exploratory factor analysis for ordinal data: A demonstration using FACTOR. Practical Assessment, Research EO Evaluation, 19, 2.

Bandura, A. (1990). Mechanisms of moral disengagement. In W. Reich (Ed.), Origins of terrorism: Psychologies, ideologies, theologies, states of mind Woodrow Wilson Center series (pp. 161-191). Cambridge: Cambridge University Press.

Bandura, A. (1991). Social cognitive theory of moral thought and action. In W.M. Kurtines \& J.L. Gewirtz (Eds.), Handbook of moral behavior and development: Theory, research and applications (vol. 1, pp. 71-129). Hillsdale, NJ: Lawrence Erlbaum Associates.

Bandura, A. (1995). Multifaceted scale of mechanisms of moral disengagement. Available from A. Bandura, Stanford University, Stanford, California, 94305-2130.

Bandura, A., Barbaranelli, C., Caprara, G.V., \& Pastorelli, C. (1996a). Mechanisms of moral disengagement in the exercise of moral agency. Journal of Personality and Social Psychology, 71, 364-374.

Bandura, A., Barbaranelli, C., Caprara, G.V., \& Pastorelli, C. (1996b). Multifaceted impact of self-efficacy befiefs on academic functioning. Child Development, 67, 1206-1222.

Bandura, A., Barbaranelli, C., Caprara, G.V., \& Pastorelli, C. (2001). Self-efficacy beliefs as shapers of children's aspirations and career trajectories. Child Development, 72, 187-206.

Barchia, K., \& Bussey, K. (2011). Individual and collective social cognitive influences on peer aggression: exploring the contribution of aggression efficacy, moral disengagement, and collective efficacy. Aggressive Behavior, 37, 107-120.

Barnes, G.M., Welte, J.W., Hoffman, J.H., \& Dintcheff, B.A. (1999). Gambling and alcohol use among youth: Influences of demographic, socialization and individual factors. Addictive Behaviors, 24, 749-767.

Boardley, I.D., \& Kavussanu, M. (2007). Development and validation of the moral disengagement in sport scale. Journal of Sport and Exercise Psychology, 29, 608-628.

Bryant, F.B., \& Yarnold, P.R. (2004). Principal-components analysis and exploratory and confirmatory factor analysis. In L.G. Grimm \& P.R. Yarnold (Eds.), Reading and understanding multivariate statistics (pp. 99-136). Washington, DC: American Psychological Association.

Byrne, B.M. (2010). Structural equation modeling with AMOS: Basic concepts, applications, and programming (2nd ed.). Ontario, Canada: Routledge.

Carroll, A., Durkin, K., Houghton, S., \& Hattie, J. (1996). An adaptation of Mak's self-reported delinquency scale for Western Australian adolescents. Australian Journal of Psychology, 48, 1-7.

Cattell, R.B. (1966). The Scree Test for the Number of Factors. Multivariate Behavioral Research, 1, $245-276$.

Cronbach, L.J., \& Meehl, P.E. (1955). Construct validity in psychological tests. Psychological Bulletin, 52, 281-302. 
Curcio, A.L., Mak, A.S., \& Knott, V.E. (2015). The Australian Self-Report Delinquency Scale: A revision. Australian Journal of Psychology, 67, 166-177.

DeVellis, R.F. (2003). Scale development: Theory and applications (vol. 26). Thousand Oaks, CA: Sage.

Fava, J.L., \& Velicer, W.F. (1992a). The effects of overextraction on factor and component analysis. Multivariate Behavioural Research, 27, 387-415.

Fava, J.L., \& Velicer, W.F. (1992b). An empirical comparison of factor, image, component, and scale scores. Multivariate Behavioural Research, 27, 301-322.

Gini, G., Pozzoli, T., \& Hymel, S. (2014). Moral disengagement among children and youth: A meta-analytic review of links to aggressive behavior. Aggressive Behavior, 40, 56-68.

Guagdagnoli, E., \& Velicer, W.F. (1988). Relation of sample size to the stability of component patterns. Psychological Bulletin, 103, 265-275.

Herrenkohl, T.I., Maguin, E., Hill, K.G., Hawkins, J.D., Abbott, R.D., \& Catalano, R.F. (2000). Developmental risk factors for youth violence. Journal of Adolescent Health, 26, $176-186$.

Jessor, R. (1992). Risk behavior in adolescence: A psychosocial framework for understanding and action. Developmental Review, 12, 374-390.

Lucidi, F., Zelli, A., Mallia, L., Grano, C., Russo, P.M., \& Violani, C. (2008). The social-cognitive mechanisms regulating adolescents' use of doping substances. Journal of Sports Sciences, 26, 447456.

Mak, A.S. (1990). Testing a psychosocial control theory of delinquency. Criminal Justice $\mathscr{E}$ Behavior, 17, 215-230.

Mak, A.S. (1993). A self-report delinquency scale for Australian adolescents. Australian Journal of Psychology, 45, 75-79.

McAlister, A.L., Bandura, A., \& Owen, S.V. (2006). Mechanisms of moral disengagement in support of military force: The impact of Sept. 11. Journal of Social and Clinical Psychology, 25, 141-165.

Mukherjee, D. (1999). Socio-economic status and school system enrolements. Sydney, Australia: Australian Centre for Equity through Education.

Newton, N.C., Barrett, E.L., Swaffield, L., \& Teesson, M. (2014). Risky cognitions associated with adolescent alcohol misuse: Moral disengagement, alcohol expectancies and perceived selfregulatory efficacy. Addictive Behaviors, 39, 165-172.

Newton, N.C., \& Bussey, K. (2006). The age of reason: The examination of psychosocial factors involved in delinquent behaviour. Sydney, Australia: Macquarie University.

Newton, N.C., Havard, A., \& Teesson, M. (2012). The association between moral disengagement, psychological distress, resistive self-regulatory efficacy and alcohol and cannabis use among adolescents in Sydney, Australia. Addiction Research E Theory, 20, 261-269.

NSW Attorney General's Department. (2003). New South Wales Children's Court Statistics. Retrieved March 20, 2005, from http://www.agd.nsw.gov.au

Obermann, M.-L. (2011). Moral disengagement in self-reported and peer-nominated school bullying. Aggressive Behavior, 37, 133-144.

Osofsky, M.J., Bandura, A., \& Zimbardo, P.G. (2005). The role of moral disengagement in the execution process. Law and Human Behavior, 29, 371-393.

Paciello, M., Fida, R., Tramontano, C., Lupinetti, C., \& Caprara, G.V. (2008). Stability and change of moral disengagement and its impact on aggression and violence in late adolescence. Child Development, 79, 1288-1309.

Passini, S. (2012). The delinquency-drug relationship: The influence of social reputation and moral disengagement. Addictive Behaviors, 37, 577-579.

Pelton, J., Gound, M., Forehand, R., \& Brody, G. (2004). The moral disengagement scale: Extension with an American minority sample. Journal of Psychopathology $\mathcal{E}$ Behavioral Assessment, 26, 31-39.

Pornari, C.D., \& Wood, J. (2010). Peer and cyber aggression in secondary school students: The role of moral disengagement, hostile attribution bias, and outcome expectancies. Aggressive Behavior, 36, 81-94. 
Pozzoli, T., Gini, G., \& Vieno, A. (2012). Individual and class moral disengagement in bullying among elementary school children. Aggressive Behavior, 38, 378-388.

Quinn, C.A., \& Bussey, K. (2015). The role of moral disengagement in underage drinking and heavy episodic drinking. Substance Use $\mathcal{E}$ Misuse, 50, 1437-1448.

Shulman, E.P., Cauffman, E., Piquero, A.R., \& Fagan, J. (2011). Moral disengagement among serious juvenile offenders: A longitudinal study of the relations between morally disengaged attitudes and offending. Developmental Psychology, 47, 1619-1632.

Velicer, W.F., \& Fava, J.L. (1987). An evaluation of the effects of variable sampling on component, image and factor analysis. Multivariate Behavioural Research, 22, 193-209.

Wagland, P., \& Bussey, K. (2005). Questioning the age of criminal responsibility (Unpublished Honours thesis). Macquarie University, Sydney.

Wagland, P., \& Bussey, K. (2015). Appreciating the wrongfulness of criminal conduct: Implications for the age of criminal responsibility. Legal and Criminological Psychology. Advance online publication. doi:10.1111/lcrp.12090

Watkins, M. (2000). Monte Carlo PCA for parallel analysis [computer software] (pp. 432-442). State College, PA: Ed \& Psych Associates. 